\title{
MEDIKOLEGAL PENGOBATAN UNTUK DIRI SENDIRI (SWAMEDIKASI) SEBAGAI UPAYA MENYEMBUHKAN PENYAKIT
}

\author{
Sumartini Dewi *
}

\begin{abstract}
It has become a habit of self-medication with non-prescription drugs done by most Indonesians. In the Regulation of the Minister of Health No. 924 / MENKES / PER / X / 1993 Regarding the Medication List of Pharmacies regulates certain hard drugs that pharmacists can give to people without a prescription. The purpose of the publication of Permenkes is to swamedikasi, a person can self-medicate rationally and supported by the pharmacy's mandatory drugs, although in general pharmacists can not sell hard drugs without a prescription, but there are certain hard drugs based on Permenkes may be sold without a doctor's prescription. The issue raised is how medikolegal swamedikasi in the perspective of healing disease? as well as how are the barriers and medicolegal swamedikasi solutions in the perspective of curing diseases? swamedikasi most places done in pharmacies, knowing drugs purchased through news media such as advertising the reason is the first attempt before treatment to health care facilities, swamedikasi actors get an explanation of doses and how to drink by pharmacist / clerk / drug seller, surveillance of swamedikasi drug use carried out with how to monitor / inspect pharmacies, the results obtained are frequent pharmacists are not in place at open pharmacy hours, selling OWA (Pharmacy Drug Compensation) without the presence of pharmacists and administrative violations. The obstacles are not yet optimal supervision from the government solution with counseling about the rule of law of drug delivery, the second barrier of the lack of awareness of drug sellers in pharmacies that do not fit the provisions of the solution by giving counseling to the owner of pharmacy facilities so as not to pursue Profit Oriented but pay attention to Patient Oriented, the third obstacle of lack of knowledge the swamediciator of the drug classes that the solution can buy is the government to increase socialization or counseling to the community about proper and responsible swamedication.
\end{abstract}

Keywords: Medikolegal, swamedikasi, Disease Healing.

\section{PENDAHULUAN}

Upaya masyarakat untuk melakukan pengobatan dengan cara pelayanan obat tanpa resep terhadap dirinya sendiri dikenal dengan istilah swamedikasi. Swamedikasi atau pengobatan mandiri adalah kegiatan atau tindakan mengobati diri sendiri dengan obat tanpa resep secara

* Sumartini Dewi, Dosen Fakultas Hukum UNTAG Semarang dapat dihubungi melalui emailsumartini.dewi@gmail.com tepat dan bertanggung jawab (rasional). ${ }^{1}$ Swamedikasi merupakan pilihan masyarakat dalam melakukan pengobatan terhadap dirinya sendiri, karena jika harus berobat ke dokter maka pasien dibebankan biaya diagnose dan biaya obat, hal ini yang menjadikan alasan mendasar mengapa banyak masyarakat masih tetap mengandalkan swamedikasi atau

1 Ipang Djunarko dan Y.Dian Hendrawati, Swamedikasi Yang Baik dan Benar,PT Citra Aji Parana,Yogyakarta,2011,hlm.6 
pengobatan mandiri tanpa dibekali keilmuan terkait obat-obatan dan penyakit yang memadai.

Kesehatan adalah keadaan sehat, baik secara fisik,mental,spiritual maupun sosial yang memungkinkan setiap orang untuk hidup produktif secara sosial dan ekonomis (Undang-undang Republik Indonesia Nomor 36 Tahun 2009 Tentang Kesehatan Pasal 1). Pembangunan kesehatan sebagai salah satu upaya pembangunan nasional diarahkan guna tercapainya kesadaran, kemauan dan kemampuan untuk hidup sehat bagi setiap penduduk agar terwujud derajat kesehatan masyarakat yang optimal. Pembangunan kesehatan bertujuan untuk meningkatkan kesadaran,kemauan dan kemampuan hidup sehat bagi setiap orang agar terwujud derajat kesehatan masyarakat yang setinggi-tingginya sebagai investasi bagi pembangunan sumber daya manusia yang produktif secara social dan ekonomis (Undang-undang Republik Indonesia Nomor 36 Tahun 2009 Tentang Kesehatan pasal 3).

Berdasarkan hasil Susenas (Survei Sosial Ekonomi Nasional) tahun 2011, ${ }^{2}$ BPS (Badan Pusat Statistik) mencatat bahwa terdapat $66,82 \%$ orang sakit di Indonesia yang melakukan upaya swamedikasi. Angka ini relative lebih tinggi dibandingkan persentase penduduk yang berobat jalan ke dokter 45,8\%. Swamedikasi sendiri bertujuan untuk meningkatkan kemampuan masyarakat dalam menolong dirinya sendiri guna mengatasi masalah kesehatan secara tepat, aman dan rasional. Obat untuk swamedikasi meliputi obat-obat yang dapat dibeli tanpa resep yang meliputi obat wajib apotik (OWA), obat bebas terbatas (OBT) dan obat bebas (OB).

Obat adalah bahan atau paduan bahan, termasuk produk biologi yang digunakan untuk mempengaruhi atau menyelidiki sistem fisiologi atau keadaan

2 http://www.bps.go.id. Diakses 5 Oktober 2016 patologi dalam rangka penetapan diagnosis, pencegahan, penyembuhan, pemulihan, peningkatan kesehatan dan kontrasepsi untuk manusia (Undangundang Republik Indonesia Nomor 36 Tahun 2009 Tentang Kesehatan pasal 1). Obat dapat didefinisikan sebagai benda atau zat yang dapat digunakan untuk merawat penyakit, membebaskan gejala, atau mengubah proses kimia dalam tubuh. Obat selama ini berperan sebagai suatu bahan atau panduan yang dimaksudkan untuk digunakan dalam menetapkan diagnosis, mencegah, menghilangkan, menyembuhkan sebagai efek terapi, mengurangi penderitaan, membuat pasien merasa nyaman serta untuk rehabilitasi. Untuk menekan biaya pengobatan, sebagian besar masyarakat seringkali mengobati penyakit yang dianggap ringan dengan obat yang dibeli tanpa resep dokter dan tidak dikonsultasikan ke dokter terlebih dahulu.

Penggunaan obat keras, seperti antibiotic tanpa resep dokter sudah merupakan hal yang umum dijumpai dalam masyarakat. Penggunaan obat keras tanpa resep dokter dapat menimbulkan masalah, misalnya penggunaan antibiotic yang tidak terkendali. Oleh sebab itu penggunaan obat keras tanpa resep dokter selalu menjadi topic hangat di masyarakat. Hal ini disebabkan karena di sejumlah apotik memang ada kecenderungan menjual obat keras tanpa resep dokter. Tidak hanya antibiotic obat keras lainnya pun dapat dibeli tanpa resep dokter di hampir semua apotik. Menurut peraturan yang berlaku, apotiker hanya boleh menjual obat keras dengan resep dokter, namun untuk meningkatkan kemampuan masyarakat dalam menolong dirinya sendiri guna mengatasi masalah kesehatan dirasa perlu ditunjang dengan sarana yang dapat meningkatkan pengobatan mandiri secara tepat,aman dan rasional, maka pemerintah menerbitkan Peraturan Menteri Kesehatan Nomor 924/MENKES/PER/X/1993 
Tentang Daftar Obat Wajib Apotik Nomor 2 yang mengatur beberapa obat keras tertentu yang dapat diberikan oleh apotiker kepada pasien tanpa resep dokter, tujuan utama diterbitkannya Peraturan Menteri Kesehatan saat ini adalah untuk swamedikasi, pasien dapat mengobati dirinya sendiri secara rasional dan ditunjang dengan adanya obat wajib apotik tersebut. Jadi meskipun secara umum apotiker tidak dapat menjual obat keras tanpa resep dokter, namun ada obat keras tertentu yang berdasarkan Peraturan Menteri Kesehatan boleh dijual tanpa resep dokter, meskipun telah ada berbagai peraturan yang mengatur mengenai penjualan obat keras tanpa resep dokter, namun kenyataan yang ada tidak sesuai dengan peraturan yang berlaku.

Berdasarkan Peraturan Menteri Kesehatan Nomor 919/MENKES/PER/ X/1993 Tentang Kriteria Obat Yang Dapat Diserahkan Tanpa Resep pada pasal 2 menyebutkan bahwa obat yang dapat diserahkan tanpa resep harus memenuhi criteria :

1. Tidak dikontraindikasikan untuk penggunaan pada wanita hamil, anak di bawah usia 2 tahun dan orang tua di atas 65 tahun

2. Pengobatan sendiri dengan obat dimaksud tidak memberikan risiko pada kelanjutan penyakit

3. Penggunaannya tidak memerlukan cara atau alat khusus yang harus dilakukan oleh tenaga kesehatan

4. Penggunaannya diperlukan untuk penyakit yang prevalensinya tinggi di Indonesia

5. Memiliki rasio khasiat keamanan yang dapat dipertanggungjawabkan untuk pengobatan sendiri.

\section{Permasalahan}

Berdasarkan latar belakang masalah di atas, maka permasalahan yang perlu untuk dikaji adalah sebagai berikut:
1. Bagaimana medikolegal pengobatan untuk diri sendiri (Swamedikasi) sebagai upaya menyembuhkan penyakit?

2. Bagaimana hambatan dan solusi medikolegal pengobatan untuk diri sendiri (Swamedikasi) sebagai upaya menyembuhkan penyakit?

\section{Pembahasan}

Medikolegal Pengobatan Untuk Diri Sendiri (Swamedikasi) Sebagai Upaya Menyembuhkan Penyakit.

1. Manfaat Swamedikasi Ditinjau Dari Segi Medis dalam penerapannya antara lain adalah :

a. Lebih mudah karena pengobatan dilakukan sendiri menggunakan obat-obatan yang mudah diperoleh.

b. Biaya yang dikeluarkan tidak banyak karena tidak harus ke rumah sakit atau dokter.

c. Kualitas pengobatan terjamin karena dilakukan sendiri, secara tidak sadar pasien akan mengupaya kan yang terbaik bagi dirinya sendiri. Penggunaan obat tanpa resep untuk swamedikasi menuntut kepastian bahwa obat tersebut terbukti aman, berkualitas dan memberikan hasil sesuai yang diharapkan

d. Aman karena obat yang dipakai adalah obat yang telah melewati serangkaian pengujian dan tertera aturan/dosis pemakaian obat.

Biaya dalam pengobatan umum terdiri dari biaya konsultasi dan biaya obat. Dalam upaya swamedikasi, biaya konsultasi dokter bisa dipangkas, selain itu penggunaan obat generic bisa lebih menghemat biaya pengobatan. Untuk melakukan pengobatan swamedikasi, pasien atau keluarga pasien harus mempunyai pengetahuan tentang penyakit yang diderita dan obat yang digunakan 
untuk mengatasi gangguan kesehatan itu. Berkembangnya teknologi informasi memudahkan pasien untuk mendapatkan informasi mengenai penyakit dan obat tersebut melalui internet.Informasi yang lengkap memberikan keberanian pada pasien untuk melakukan pengobatan swamedikasi.

Setiap orang yang melakukan swamedikasi juga harus menyadari kelebihan ataupun kekurangan dari pengobatan yang dilakukan, dengan mengetahui manfaat dan resikonya, maka pasien dapat melakukan penilaian apakah pengobatan tersebut perlu dilakukan atau tidak, bila gejala tidak membaik atau tidak sembuh dalam waktu tiga hari, segera berobat ke dokter untuk mendapat penanganan yang lebih baik. Bila muncul gejala seperti sesak napas, kulit kemerahan, gatal, bengkak di bagian tertentu, mual dan muntah, maka kemungkinan telah terjadi gejala efek samping obat atau reaksi alergi terhadap obat yang diminum. Segera hentikan pengobatan dan periksa ke dokter untuk mendapatkan penanganan medis.

2. Regulasi Yang Mengatur Obat Swamedikasi

Jenis obat yang boleh digunakan dalam swamedikasi adalah :

a. Obat OTC ( Over the counter) tanpa resep dokter yang terdiri dari :

1. Obat bebas : tanda lingkaran hitam, dasarhijau

2. Obat terbatas : tanda lingkaran hitam, dasar biru

b. Obat Wajib Apotik (OWA), yaitu obat keras (tanda lingkaran hitam,dasar merah dengan huruf $\mathrm{K}$ besar ) yang dapat dibeli di apotik tanpa resep dokter, tetapi harus diserahkan langsung oleh seorang apoteker kepada pasien disertai dengan informasi lengkap tentang penggunaan obat.

C. Suplemen makanan (vitamin, kalsium d1l), biasanya digunakan untuk memenuhi kebutuhan vitamin dalam tubuh, seperti kekurangan vitamin
B1,B6 dan B12 pada penyakit Polyneuritis

Obat-obatan yang beredar di Indonesia digolongkan ke dalam beberapa kelompok sebagai berikut: ${ }^{3}$

1. Kelompok Obat Bebas, obat dalam golongan ini dapat diperjualbelikan bebas, tanpa resep dokter dan dapat dibeli di apotik atau took obat. Tanda khususnya berupa warna hijau di dalam lingkaran warna hitam

2. Kelompok obat bebas terbatas, obat ini disebut juga daftar W (Waarschuing adalah peringatan). Golongan ini dapat diperjualbelikan secara bebas dengan jumlah terbatas dan disertai tanda peringatan. Tanda peringatan ditulis dengan huruf putih di atas kertas berwarna hitam,yang terdiri dari enam macam yaitu :

a. Peringatan No.1 : Awas! Obat Keras. Bacalah aturan memakainya

b. Peringatan No.2 : Awas! Obat Keras. Hanya untuk kumur, jangan ditelan.

c. Peringatan No.3 : Awas! Obat Keras. Hanya untuk bagian luar badan

d. Peringatan No.4 : Awas! Obat Keras. Hanya untuk dibakar (untuk rokok asma).

e. Peringatan No.5 : Awas! Obat Keras. Tidak boleh ditelan.

f. Peringatan No.6 : Awas! Obat Keras. Obat Wasir. Jangan ditelan.

3. Kelompok obat keras dan psikotropika, obat ini terkenal obat golongan daftar $\mathrm{G}$ (gevaarlijk adalah berbahaya). Golongan ini sangat berbahaya mempunyai efek samping yang sangat besar dan untuk mendapatkannya perlu resep dokter. Obat Psikotropika adalah obat keras baik alamiah maupun sintetis bukan narkotik, yang berkhasiat psikoaktif melalui pengaruh selektif pada susunan saraf pusat yang

3 Yosef Wijoyo, Penggolongan Obat,PT.Citra Aji Parana, Yogyakarta,2011,hlm.3 
menyebabkan perubahan khas pada aktivitas mental dan perilaku.

Beberapa ketentuan mengenai obat daftar G/obat keras :

a. Pada bungkus luar harus disebutkan bahwa obat itu hanya boleh diserahkan dengan resep dokter.

b. Semua obat baru dimasukkan ke dalam daftar G, kecuali apabila oleh Kementerian Kesehatan telah dinyata kan secara tertulis bahwa obat baru itu tidak membahayakan kesehatan manusia.

c. Obat baru adalah semua obat yang tidak tercantum dalam Farmakope Indonesia dan Daftar Obat Keras atau obat yang secara resmi,belum pernah diimpor atau digunakan di Indonesia, sehingga tidak diketahui khasiat dan keamanannya.

d. Kecuali bila ditentukan lain, maka semua bahan yang tergolong obat daftar $\mathrm{G}$, berlaku bagi obat itu sebagai substansi dan juga bagi semua sediaan yang mengandung obat tersebut.

Sedangkan obat psikotropika adalah obat yang mempengaruhi susunan saraf pusat dengan cara menyebabkan depresi susunan syaraf pusat. Istilah-istilah lain yang digunakan adalah psikomimetik, psikotogenik yaitu suatu bahan halusinogen dapat memberikan halusinasi, termasuk halusinogen :semua obat serta semua sediaan yang mengandung obat berikut :

1. LSD atau LSD-25, DMT, DMNP, THC, STP, DOM, Mescaline, Psilocine, Psilocybin.

2. Semua isomer dari 3-methyl-2phenylmorpholine.

3. Perangsang susunan saraf pusat : Amfetamin, Deksamfetamin, Metamfetamin, Metilfenidat, Pipradrol.

4. Penekan susunan saraf pusat : Barbitural dan semua derivate serta garamnya antara lain Fenobarbital, Amobarbital,Pentobarbital dan Hipnotika antara lain Metilprilon,

\section{Metakualon}

4. Kelompok Narkotika :

Obat ini juga obat daftar O ( Opium ) dan hanya dapat diperoleh di apotik dengan resep dokter. Obat narkotika merupakan zat atau obat yang berasal dari tanaman atau bukan tanaman baik sinpenelitian maupun semi sinpenelitian yang dapat menyebabkan penurunan atau perubahan kesadaran, hilangnya rasa, mengurangi sampai menghilangkan rasa nyeri dan dapat menimbulkan ketergantungan. Obat ini pada kemasannya ditandai dengan lingkaran yang di dalamnya terdapat palang $(+)$ berwarna merah. Obat Narkotika bersifat adiksi dan penggunaannya diawasi dengan ketat, sehingga obat golongan narkotika hanya diperoleh di apotik dengan resep dokter asli (tidak dapat menggunakan copy resep). Contoh dari obat narkotika antara lain : opium, coca, ganjal marijuana, morfin, heroin dan lain sebagainya. Dalam bidang kesehatan, obat-obat narkotika biasa digunakan sebagai anestesi/ obat bius dan analgetik/obat penghilang rasa sakit.

Dalam penggolongan obat di atas, golongan obat keras, narkotika dan golongan psikotropika tidak diperbolehkan dijual secara bebas di apotik tanpa resep dokter, tetapi pemerintah menerbitkan peraturan yang mengatur tentang Obat Wajib Apotik (OWA). Obat Wajib Apotik (OWA) adalah obat keras yang dapat diserahkan oleh apoteker pengelola apotik tanpa resep dokter, hal tersebut diatur dalam Peraturan Menteri Kesehatan No.922/ MENKES/PER/X/1993 tentang Ketentuan Dan Tata Cara Pemberian Izin Apotik pasal 18 ayat (1) disebutkan bahwa "Apoteker Pengelola Apotik, Apoteker Pendamping atau Apoteker Pengganti diizinkan untuk menjual obat keras yang dinyatakan sebagai Daftar Obat Wajib Apotik tanpa resep". Tujuan dibuatnya daftar OWA adalah untuk meningkatkan kemampuan 
masyarakat dalam menolong dirinya sendiri guna mengatasi masalah kesehatan, sehingga dirasa perlu ditunjang dengan sarana yang dapat meningkatkan pengobatan sendiri secara tepat, aman dan rasional.

\section{Hambatan dan solusi medikolegal pengobatan untuk diri sendiri (Swamedikasi) sebagai upaya menyembuhkan penyakit.}

Upaya pengaturan terhadap swamedikasi dan penjualan obat tanpa resep sacara normatif sudah dilaksanakan oleh pemerintah, namun pada perkembangannya pengaturan tersebut tidak mampu membatasi keinginan masyarakat untuk mendapatkan obat yang tidak termasuk obat bebas, obat bebas terbatas dan obat wajib apotik dalam upaya melakukan swamedikasi.

1. Hambatan - hambatan dalam pelaksanaan swamedikasi dalam perspektif penyembuhan penyakit yaitu :

a. Belum optimalnya pengawasan dari pemerintah;

Selama ini upaya pemerintah dalam mengawasi peredaran obat yang digunakan dalam upaya pelaksana an swamedikasi masih lemah. Hal tersebut dapat dilihat masih banyak dijumpai apotik yang menjual obat OWA tanpa kehadiran apoteker tetapi hanya dilayani oleh asisten apoteker. Fakta di lapangan juga dijumpai apotik memberikan obat keras tanpa resep dokter, misalnya antibiotik amoxicillin $500 \mathrm{mg}$.

b. Kurangnya kesadaran penjual obat di apotik yang tidak sesuai ketentuan peraturan perundangundangan;

Salah satu hambatan dalam pelaksanaan upaya swamedikasi adalah kurangnya kesadaran penjual obat di apotik yang tidak sesuai ketentuan. Faktor utama penjual obat di apotik yang tidak sesuai ketentuan. Faktor utama penjual dalam hal ini apoteker/ asisten apoteker dalam melakukan penjualan obat. Orientasi dari suatu apotik yang masih mengarah pada profit oriented menyebabkan obat yang seharusnya dilarang penjualan nya tanpa resep dokter masih dapat dengan bebas dibeli di apotik tanpa resep dokter. Pencapaian omset suatu apotik merupakan hal utama yang dituntut oleh para pemilik sarana apotik.

c. Kurangnya pengetahuan pelaku swamedikasi tentang golongan obat yang dapat dibeli dalam upaya swamedikasi;

Sebagian besar pelaku swamedikasi tidak memahami tentang penggolongan obat, sehingga dalam upaya swamedikasi mereka beranggapan bahwa dapat membeli semua obat yang diinginkan di apotik/toko obat, padahal golongan obat yang boleh dibeli di apotik adalah obat bebas dan bebas terbatas serta OWA (Obat Wajib Apotik), khusus OWA hanya boleh dibeli dan diserahkan oleh apoteker,sedangkan pada toko obat hanya menyediakan obat bebas dan obat bebas terbatas.

2. Solusi medikolegal pengobatan untuk diri sendiri (Swamedikasi) sebagai upaya menyembuhkan penyakit.

Upaya dilakukan untuk mengatasi hambatan tersebut adalah:

a. Solusi yang bisa dilakukan yaitu dengan langkah konkrit dari pemerintah melalui penyuluhan tentang aturan hukum pemberian obat swamedikasi terhadap apotik. Apabila telah dilakukan penyuluh an masih saja menjual obat keras tidak sesuai dengan aturan maka Dinas Kesehatan akan menindak 
dengan memberikan peringatan, pembekuan ijin apotik sampai dengan memberikan peringatan, pembekuan ijin apotik sampai dengan pencabutan ijin apotik yang bersangkutan. Namun apabila dalam penyaluran obat keras tersebut terbukti sebagai suatu tindakan pidana sesuai yang diatur dalam perundang-undangan, maka dinas kesehatan bekerjasama dengan BBPOM melalui Penyidik Pegawai Negeri Sipil (PPNS) dapat menindaklanjuti dengan pro justitia, dengan adanya koordinasi yang baik antara instansi yang berwenang yaitu Dinas Kesehatan dan BBPOM dalam pembinaan apotik sebagai suatu sarana yang diijinkan menyalurkan obat keras, maka diharapkan kontrol terhadap peredaran obat keras dapat lebih maksimal.

b. Untuk mengatasi hambatan kurangnya kesadaran penjual obat di apotek yang tidak sesuai ketentuan yaitu dari IAI (Ikatan Apotek Indonesia) organisasi profesi apoteker memberikan masukan kepada pemerintah khususnya Dinas Kesehatan, solusinya memberikan penyuluhan kepada Pemilik Sarana Apotek (PSA) supaya tidak hanya mengejar Profit Orientedtetapi memperhati kan Patient Oriented.

c. Untuk mengatasi hambatan kurang nya pengetahuan pelaku swa medikasi tentang golongan obat yang dapat dibeli dalam upaya swamedikasi maka pemerintah harus meningkatkan sosialisasi atau penyuluhan kepada masyarakat tentang swamedikasi yang benar dan bertanggung jawab serta penyuluhan tentang golongan obat yang dapat dibeli dalam upaya swamedikasi.

\section{Kesimpulan}

Dari uraian pembahasan di atas dapat ditarik kesimpulan mengenai medikolegal pengobatan mandiri atau swamedikasi dalam perspektif penyembuh an penyakit:

1. Medikolegal pengobatan mandiri atau swamedikasi dalam perspektif penyembuhan penyakit dari "segi medis" dilaksanakan dengan pelaku swamedikasi memegang tanggung jawab penuh terhadap obat yang digunakan. Oleh sebab itu sebelum mengkonsumsi obat sebaiknya membaca label dan brosur obat dengan seksama dan teliti. Jika pasien memilih untuk melakukan pengobatan sendiri, maka ia harus dapat mengenali gejala yang dirasakan, menentukan apakah kondisi mereka sesuai untuk pengobatan sendiri atau tidak, memilih produk obat yang sesuai dengan kondisinya, mengetahui ada atau tidaknya riwayat alergi terhadap obat yang digunakan, mengikuti petunjuk yang tertera pada label obat yang dikonsumsi.

Sedangkan dari "segi yuridis" adalah berdasarkan Peraturan Menteri Kesehatan Nomor 919/Menkes/Per/X/ 1993 Tentang Kriteria Obat Yang Dapat Diserahkan Tanpa Resep. Mengenai obat yang boleh dibeli dalam upaya swamedikasi hanya obat bebas dan bebas terbatas serta OWA (Obat Wajib Apotik), khusus OWA hanya boleh dibeli dan diserahkan oleh apoteker.

2. Hambatan dan solusi medikolegal pengobatan mandiri atau swamedikasi dalam perspektif penyembuhan penyakitadalah

a. Belum optimalnya pengawasan dari pemerintah, solusi yang dapat dilakukan dengan penyuluhan tentang aturan hukum pemberian obat swamedikasi terhadap apotik.

b. Kurangnya kesadaran penjual obatd 
di apotik yang tidak sesuai ketentuan, solusi untuk mengatasi nya adalah dengan memberikan penyuluhan kepada Pemilik Sarana Apotik (PSA) tidak hanya mengejar Profit Oriented tetapi memperhati kan Patient Oriented.

c. Kurangnya pengetahuan pelaku swamedikasi tentang golongan obat yang dapat dibeli dalam upaya swamedikasi, solusinya adalah pemerintah harus meningkatkan sosialisasi atau penyuluhan kepada masyarakat tentang swamedikasi yang benar dan bertanggung jawab serta penyuluhan tentang golongan obat yang dapat dibeli dalam upaya swamedikasi

\section{Saran}

Pemerintah agar meningkatkan pengawasan dan monitoring / pemeriksaan kepada apotik / toko obat mengenai penjualan obat kepada masyarakat khususnya di luar golongan obat bebas, obat bebas terbatas dan obat wajib apotik (OWA) sehingga masyarakat mendapatkan kepastian keamanan obat saat swamedikasi dan melaksanakan penyuluhan kepada apoteker/penjual obat agar memberikan informasi dan edukasi kepada pelaku swamedikasi.

Dinas Kesehatan harus melakukan penyuluhan kepada masyarakat tentang aturan swamedikasi, bahaya swamedikasi dan swamedikasi yang tepat dan bertanggung jawab.
Pelaku swamedikasi agar lebih aktif bertanya kepada apoteker atau tenaga kefarmasian lainnya supaya tepat mendapatkan obat, tepat dosisnya dengan efek samping

\section{DAFTAR PUSTAKA}

Ipang Djunarko dan Y.Dian Hendrawati, 2011, Swamedikasi Yang Baik dan Benar, PT Citra Aji Parana, Yogyakarta.

Septadina,I.S,2008, Penggunaan Analgesik Untuk Mengatasi Sakit Kepala Pada Masyarakat Perkotaan, Universitas Sriwijaya

Suryawati S, 1997, Mепијu Swamedikasi Yang Rasional. Pusat Studi Farmakologi Klinik Dan Kebijakan Obat, Universitas Gajah Mada : Yogyakarta.

Yosef Wijoyo, 2011, Penggolongan Obat, PT.Citra Aji Parana, Yogyakarta.

Peraturan Perundang-undangan

Undang-undang Republik Indonesia Nomor 36 Tahun 2009 Tentang Kesehatan

Permenkes Nomor 919/Menkes/Per/X/ 1993 Tentang Kriteria Obat Yang Dapat Diserahkan Tanpa Resep

Kepmenkes Nomor 924/Menkes/Per/X/ 1993 Tentang Daftar Obat Wajib Apotik

Internet

http://www.bps.go.id 